\begin{tabular}{lc|}
\hline UDD & $\begin{array}{c}\text { Jurnal Cakrawala Promkes } \\
\text { Vol. 3, No. 2,Agustus 2021, pp. 61-69 } \\
\text { https://doi.org/10.12928/promkes.v1i1.xx } \\
\text { http://journal2.uad.ac.id/index.php/cp/index }\end{array}$ \\
$\begin{array}{l}\text { Universitas } \\
\text { Ahmad Dahlan }\end{array}$ & \\
\hline
\end{tabular}

\title{
Pengalaman pemberian ASI ekslusif pada Ibu bekerja: scoping review
}

\author{
Dinar Agustin,a.1*, Andari Wuri Astutia.2 \\ a Universitas Aisyiyah Yogyakarta, Sleman, Yogyakarta. 55292, Indonesia; \\ ${ }^{1}$ Agustindinar40@gmail.com; ${ }^{2}$ astutiandari@unisayogya.ac.id; \\ *Correspondent Author
}

ARTICLE INFO

Article history

Received: $28-7-2021$

Revised : 25-8-2021

Accepted : 3-9-2021

Keywords

Massage Counterpressure, Nyeri Persalinan

\begin{abstract}
Working mothers faced many challenges and constraints. Despite legislations mandating workplaces to give support, including breastfeeding areas for their employees, a number of hurdles remained, preventing them from achieving exclusive breastfeeding (EBF). Therefore, this review intended to review evidence on the experience of $E B F$ practices among working mothers. This study employed scoping review by using four stages. Firstly, develop the focus of the study through the framework of PEOS (Population, Exposure, Outcome and study design). Secondly, conducted literature search using three relevant databases (PubMed, Science Direct, Wiley Online) and grey literature (Google scholar). Thirdly, selected relevant studies using inclusion and exclusion criteria. Fourthly, conducted critical appraisals using data charting to assess the quality of included articles, followed by analyzing and reporting the results. PRISMA flowchart was used to describe the literature search plot. Based on 12 included articles, twothirds of the included articles were qualitative studies categorized as grade $A$. The other four articles had grade $B$ where three out of four were non-randomized quantitative studies and one mixed-method study. Some factors identified to be the cause to prevent continued EBF were insufficiency support and facilities from family, husband, coworkers in the workplaces (paid leave, availability of daycare, lactation room, breast milk pumping tools). Two other identified factors were previous breastfeeding experience and knowledge. The implementation of EBF practices were challenging in some developed countries. However, having good knowledge was necessary to reduce the gap between maternal perception and belief in which was occurred in Italy study. In contrary, low knowledge was found as an important obstacle in the developing world such as Bangladesh. Overall, perception and belief related to EBF of working mothers contributed to the practice of EBF.
\end{abstract}

This is an open-access article under the CC-BY-SA license.

\section{Introduction}

Menurut World Breastfeeding Week tahun 2018, hanyal 33,6\% dari 137.700 .000 bayi yang lahir di seluruh dunia menerima ASI hanya saat mereka berusia nol hingga enam bulan. Data Badan Kesehatan Dunia (WHO) tahun 2018 juga menunjukkan bahwa proporsi rata-rata pemberian ASI eksklusif di dunia hanya (38\%), padahal target pemberian ASI WHO adalah 80\%. Tindakan kolektif diperlukan untuk mencapai tujuan mencapai setidaknya 60\% menyusui eksklusif selama enam bulan pada tahun 2025 (1). Namun demikian, ibu masih menghadapi berbagai kendala untuk mendapatkan ASI yang optimal, salah satu kendala terbesarnya adalah ketika ibu harus bekerja kurang mendapat dukungan untuk terus memberikan ASI eksklusif. 
Mengingat bahwa dokumen hukum menetapkan bahwa perlindungan sosial orang tua yang setara bagi laki-laki dan perempuan mencakup beberapa hal, seperti cuti melahirkan bahkan cuti berbayar dan tunjangan kerja, hal ini dapat menciptakan lingkungan yang memungkinkan untuk menyusui baik di sektor kerja formal maupun informal (2).

Berdasarkan beberapa laporan penelitian tentang masalah ASI Eksklusif di Indonesia, dilaporkan bahwa faktor-faktor penyebab ibu tidak menyusui antara lain adalah kesibukan ibu bekerja, pendidikan ibu yang rendah, promosi penggunaan susu formula yang masif, penurunan sekresi ASI (3). Penelitian lain menunjukkan bahwa ibu yang kembali bekerja penuh waktu menghabiskan lebih sedikit waktu untuk memberikan ASI eksklusif dibandingkan ibu yang memilih untuk tinggal di rumah dan tidak bekerja (4). Hasil penelitian hampir sama dengan hasil penelitian (5) menemukan durasi pemberian ASI pada ibu yang bekerja lebih singkat dari pada durasi pemberian ASI pada ibu tidak bekerja. Akan tetapi penelitian lain menunjukkan bahwa wanita yang mendapatkan cuti melahirkan kurang dari 6 minggu setelah melahirkan cenderung untuk tidak mulai menyusui bayinya. (6).

Peningkatan angkatan kerja perempuan juga menjadi salah satu kendala keberhasilan program ASI Eksklusif, karena cuti melahirkan hanya diberikan 12 minggu bagi Aparatur Sipil Negara dan 40 hari bagi sebagian besar pegawai swasta (7). Oleh sebab itu, ibu yang bekerja di Indonesia hanya bisa secara intensif mendampingi bayinya selama 1-3 bulan, termasuk menyusui bayinya. Setelah itu ibu harus kembali bekerja, sehingga sering kali ibu terpaksa berhenti menyusui. Agar pemberian ASI ekslusif selama enam bulan dapat dilakukan oleh ibu bekerja yang menyusui, dibutuhkan dukungan yang memadai dan motivasi yang kuat dari lingkungan keluarga dan pimpinan/rekan kerjanya (8).-Penelitian mengenai faktor yang mempengaruhi keberhasilan ibu menyusui ASI ekslusif sudah banyak dilakukan, namun topik tersebut belum banyak ditemukan dengan metode scoping review. Scoping review ini bertujuan untuk mereview evidence tentang pengalaman praktik menyusui ASI eksklusif pada ibu bekerja. Keberhasilan dari penelitian ini dapat memberikan pengetahuan serta inovasi tidak hanya pada ibu bekerja saja melainkan bermanfaat bagi masyarakat. Berdasarkan hal tersebut, pertanyaan penelitian scoping review ini: "bagaimana pengalaman tantangan praktik pemberian ASI eksklusif pada ibu bekerja?".

\section{Metode}

Studi ini merupakan scoping review. Dalam menyusun scoping review ada beberapa tahapan yang harus peneliti lakukan. Tahapan ini tertuju pada (9) mengenai kerangka kerja penyusunan scoping review. Permasalahan yang ditemukan dalam review ini yaitu pengalaman praktik pemberian ASI eksklusif pada ibu bekerja. Langkah pertama dalam melakukan scoping review adalah menentukan apa yang akan dicari dengan menggunakan framework model Population, Exposure, Outcome, Study Design (PEOS). PEOS memfasilitasi pembentukan pertanyaan dan memfasilitasi pencarian literature. Proses ini mengidentifikasi konsep-konsep kunci untuk strategi pencarian yang efektif. Langkah berikutnya, melakukan pencarian literature evidence digunakan database yang relevan yaitu menggunakan database PubMed, Wiley Online Library dan Science Direct.. Pencarian dengan menggunakan database Wiley Online Library akan diakses melalui Unisa Library, PubMed diakses melalui Google, sedangkan untuk Science Direct menggunakan akses dari PNRI. Sedangkan pencarian literature dengan grey literatur menggunakan google scholar. Setelah menentukan database yang relevan, kemudian peneliti membuat kata kunci proses pencarian yang dimasukkan menggunakan Medical Subject Headings $(\mathrm{MeSH})$ diantaranya yang digunakan yaitu yaitu memasukan keyword yang sesuai dengan tema (work* mothers*) OR work* moms*) AND breastfeed*) OR exclusive breastfeed*) AND practice*) OR implementation*) OR application*AND experience*) OR support*) OR view*) OR factor*).

Berikut adalah tabel framework dari permasalahan yang teridentifikasi dengan menggunakan PEOS. 
Tabel 2.1. Framework untuk menentukan kelayakascoping review

\begin{tabular}{ll}
\hline Population & Ibu bekerja yang menyusi \\
\hline Exposure & Praktek pemberian ASI eksklusif \\
\hline Outcome & Pengalaman \\
\hline Study design & Kualitatif, Cross Sectional, Mixed-method \\
\hline
\end{tabular}

Seleksi dari artikel menggunakan kriteria inklusi dan eksklusi. Kriteria inklusi adalah artikel yang diterbitkan artikel diterbitkan sejak tahun 2010 sampai dengan 2020, Artikel di terbitkan dalam bahasa Inggris atau bahasa Indonesia. Sedangkan kriteria eksklusinya adalah makalah opini, ulasan makalah, commentary, ulasan buku.

Proses seleksi secara trasnparan bisa dilihat dalam PRISMA Flowchart sebagai berikut:
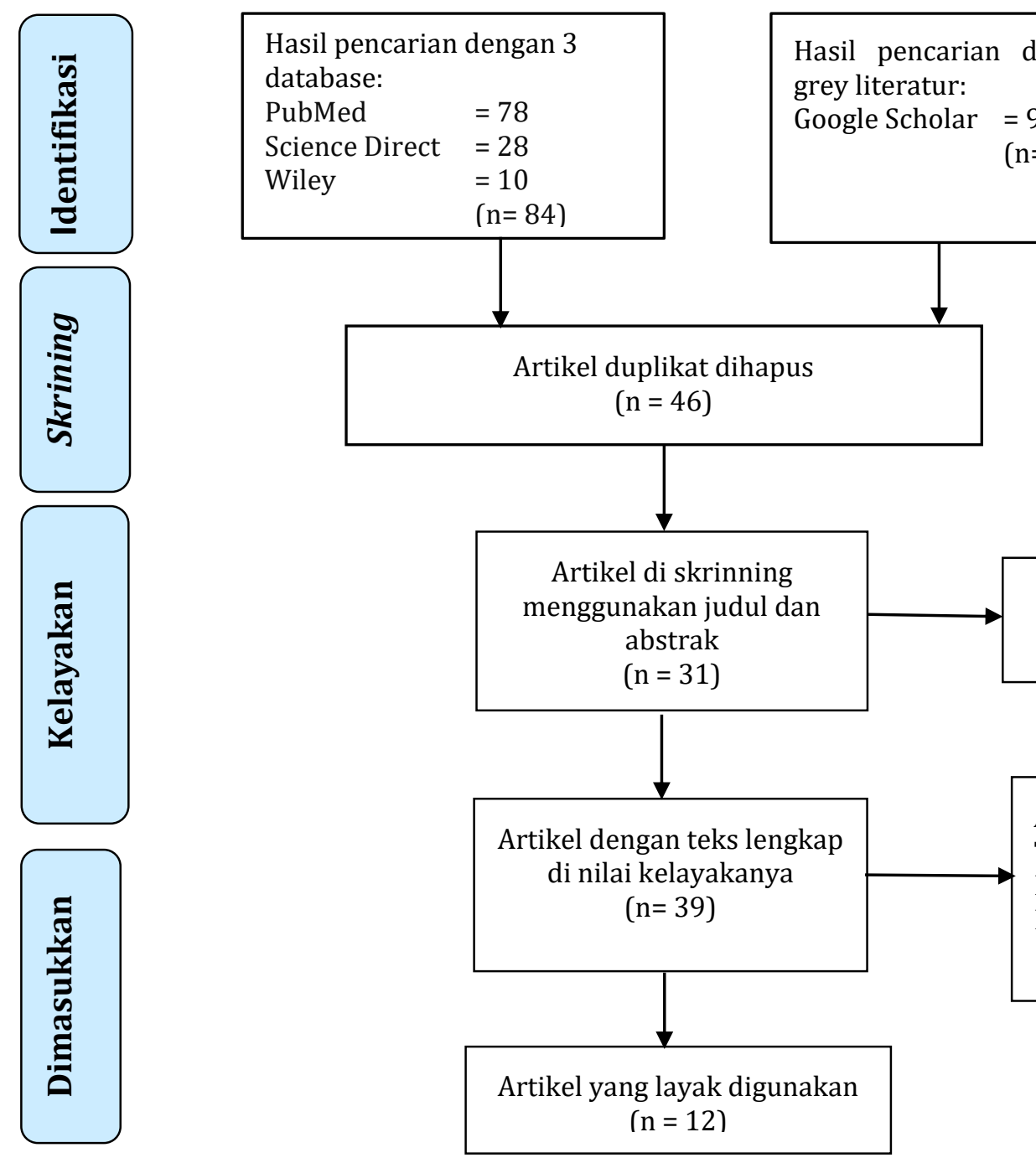

Artikel tidak relevan $(n=28)$

Hasil pencarian dengan 3 database didapatkan 78 artikel dari Pubmed, 28 artikel dari science direct, 10 artikel dari wiley total di dapatkan 84 dan dilakukan pencarian juga dengan google scholar di dapatkan 94 artikel. Dari total artikel yang didapatkan yaitu sejumlah 178 artikel yang telah dipilih, kemudian dilakukan eliminasi artikel terdapat 46 artikel duplikat. Selanjutnya di skrining menggunakan judul dan abstrak artike terdapat 31 artikel. Sejumlah 28 artikel tidak relevan dikeluarkan berdasarkan identifikasi review artikel yang dikecualikan. Selanjutnya 
dilakukan full-text reading artikel untuk dinilai kelayakannya diperoleh 39 artikel yang dikeluarkan. 22 artikel dikeluarkan dengan alasan 11 artikel tujuannya tidak sesuai, 5 artikel terdapat metode tidak sesuai dan 6 artikel populasi tidak sesuai. Jadi hasil akhir dari pemilihan artikel yang layak digunakan untuk scoping review didapatkan 12 artikel.

\section{Hasil dan Pembahasan}

\section{Kualitas penelitian}

Critical appraisal dilakukan untuk mengetahui kualitas artikel yang dipilih. Alat yang digunakan dalam scoping review ini yakni Mixed-Method Appraisal Tool (MMAT) (10). Berikut rentang nilai critical appraisal yang ditentukan oleh peneliti.

Tabel 3.1. Rentang nilai critical appraisal

\begin{tabular}{lll}
\hline Rentang penelitian & Grade & Kategori \\
\hline $10-14$ & A & Baik \\
\hline $5-9$ & B & Cukup Baik \\
\hline $0-4$ & C & Kurang Baik \\
\hline
\end{tabular}

Critical appraisal menggunakan MMAT bisa dilihat dalam table MMAT berikut:

Pada tahap critical appraisal ini, terdapat 12 artikel yang dipilih sesuai dengan topik dengan desain penelitian yang digunakan yakni metode campuran, kuantitatif non-diacak dan kualitatif. Kemudian dilakukan pengkategorian kualitas artikel dengan skala grade A (Baik), B (Cukup Baik) dan C (Kurang Baik) untuk menilai kualitas tiap artikel.

Tabel 3.2. Panduan Mixed Method Appraisal Tool (MMAT)

\begin{tabular}{|c|c|c|}
\hline No & $\begin{array}{l}\text { Kategori } \\
\text { desain } \\
\text { studi }\end{array}$ & Kriteria kualitas metodologis \\
\hline & $\begin{array}{l}\text { Pertanyaan } \\
\text { penyaringan } \\
\text { (untuk } \\
\text { semua jenis) }\end{array}$ & $\begin{array}{l}\text { S1. Apakah ada pertanyaan penelitian yang jelas? } \\
\text { S2. Apakah data yang dikumpulkan memungkinkan untuk menjawab } \\
\text { pertanyaan penelitian? } \\
\text { Note : Penilaian lebih lanjut mungkin tidak dapat dilakukan atau tidak } \\
\text { sesuai jika jawabannya 'Tidak' atau 'Tidak dapat menjawab' untuk } \\
\text { satu atau kedua pertanyaan saringan. }\end{array}$ \\
\hline 1. & Kualitatif & $\begin{array}{l}\text { 1.1. Apakah pendekatan kualitatif tepat untuk menjawab pertanyaan } \\
\text { penelitian? } \\
\text { 1.2. Apakah metode pengumpulan data kualitatif memadai untuk } \\
\text { menjawab pertanyaan penelitian? } \\
\text { 1.3. Apakah temuan cukup diperoleh dari data? } \\
\text { 1.4. Apakah interpretasi hasil cukup didukung oleh data? } \\
\text { 1.5. Apakah ada koherensi antara sumber data kualitatif, pengumpulan, } \\
\text { analisis, dan interpretasi? }\end{array}$ \\
\hline 2. & $\begin{array}{l}\text { Kuantitatif } \\
\text { non- } \\
\text { Diacak }\end{array}$ & $\begin{array}{l}\text { 2.1. Apakah peserta mewakili populasi sasaran? } \\
\text { 2.2. Apakah pengukuran tepat mengenai hasil dan intervensi (atau } \\
\text { paparan)? } \\
\text { 2.3. Apakah ada data hasil yang lengkap? } \\
\text { 2.4. Apakah perancu diperhitungkan dalam desain dan analisis? } \\
\text { 2.5. Selama masa studi, apakah intervensi diberikan (atau paparan terjadi) } \\
\text { sebagaimana dimaksud? }\end{array}$ \\
\hline 3. & $\begin{array}{l}\text { Metode } \\
\text { campuran }\end{array}$ & $\begin{array}{l}\text { 3.1. Apakah ada alasan yang memadai untuk menggunakan desain metode } \\
\text { campuran untuk menjawab pertanyaan penelitian? }\end{array}$ \\
\hline
\end{tabular}




\begin{tabular}{|l|l|}
\hline 3.2. Apakah komponen penelitian yang berbeda terintegrasi secara efektif \\
untuk menjawab pertanyaan penelitian? \\
3.3. Apakah keluaran dari integrasi komponen kualitatif dan kuantitatif \\
diinterpretasikan secara memadai? \\
3.4. Apakah perbedaan dan inkonsistensi antara hasil kuantitatif dan \\
kualitatif ditangani secara memadai? \\
3.5. Apakah komponen penelitian yang berbeda mematuhi kriteria kualitas \\
dari setiap tradisi metode yang terlibat?
\end{tabular}

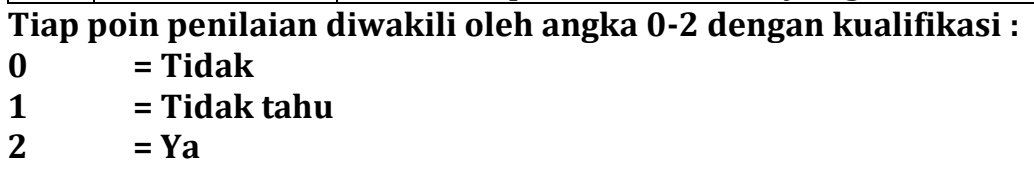

Tabel 3.3. Hasil Panduan MMAT studi yang termasuk dalam penelitian ini

\begin{tabular}{|c|c|c|}
\hline No & Author (year) & Score (kesimpulan kualitas) \\
\hline \multicolumn{3}{|c|}{ Penelitian kuantitatif non-diacak } \\
\hline 1. & (11) Nkrumah, (2017) & $8 / \mathrm{B}$ \\
\hline 2. & (12) Cervera-Gasch et al., (2020) & 9/B \\
\hline 3. & (13) Dun-Dery \& Laar, (2016) & $9 / \mathrm{B}$ \\
\hline \multicolumn{3}{|c|}{ Penelitian Kualitatif } \\
\hline 4. & (14) Abekah-Nkrumah et al., (2020) & $14 / \mathrm{A}$ \\
\hline 5. & (15) Riaz \& Condon, (2019) & $13 / \mathrm{A}$ \\
\hline 6. & (16) Mabaso et al., (2020) & $12 / \mathrm{A}$ \\
\hline 7. & (17) Valizadeh et al., (2017) & $13 / \mathrm{A}$ \\
\hline 8. & (18) Payne \& Nicholls, (2010) & $11 / \mathrm{A}$ \\
\hline 9. & (19) Hasan et al., (2020) & $12 / \mathrm{A}$ \\
\hline 10. & (20) Truong Xuan \& Nguyen, (2018) & $12 / \mathrm{A}$ \\
\hline 11. & (21) Sari et al., (2015) & $14 / \mathrm{A}$ \\
\hline \multicolumn{3}{|c|}{ Penelitian Metode campuran } \\
\hline 12. & (22) Chen et al., (2019) & $9 / \mathrm{B}$ \\
\hline
\end{tabular}

Karakteristik studi berdasarkan negara

Pada artikel yang didapatkan, dibedakan atas artikel dari negara berkembang yaitu satu artikel dari Pakistan, satu artikel dari Indonesia, satu artikel dari Vietnam, satu artikel dari Bangladesh, satu artikel dari Cina, tiga artikel dari Ghana, Afrika Barat. Dari negara maju didapat dua artikel dari Turki dan satu dari Spanyol serta satu artikel dari Selandia Baru.

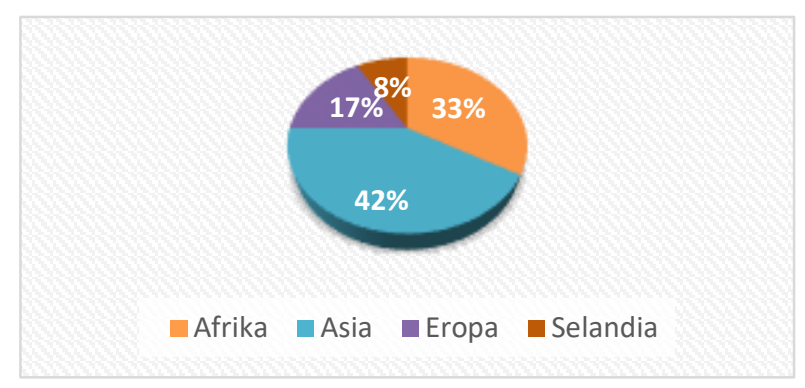

Karakteristik studi berdasarkan negara 
Berdasarkan 12 artikel yang dipilih, kemudian ekstraksi data dilakukan untuk mengklasifikasikan beberapa poin atau bagian dari tujuan penelitian artikel, desain penelitian, ukuran sampel, hasil atau temuan penelitian. 12 artikel terpilih menggunakan rancangan penelitian kualitatif sebanyak 8 artikel, 3 artikel penelitian kuantitatif non-diacak dan metode campuran sebanyak 1 artikel.

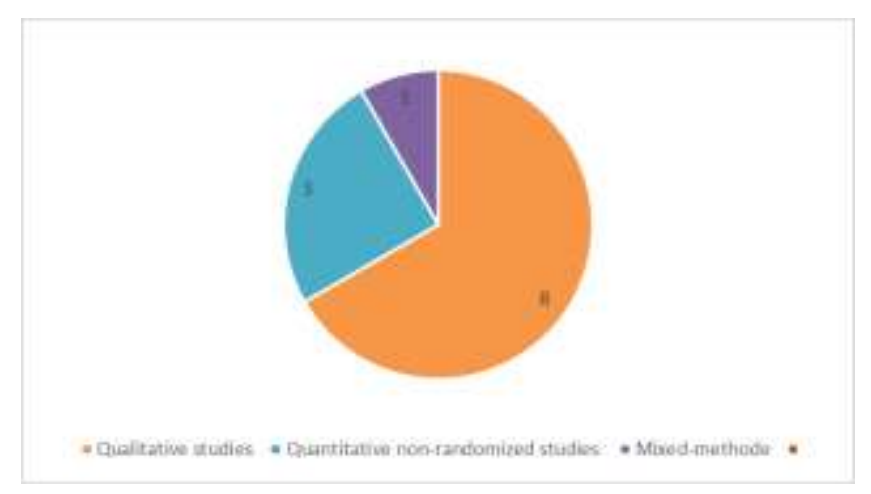

Gambar 3.2. Analisis berdasarkan Jenis Studi

Karakteristik studi berdasarkan kualitas / nilai

Setiap metode penelitian memiliki checklist critical appraisal yang berbeda. Artikel yang berkualitas baik, yaitu nilai A adalah 8 artikel, dan nilai B adalah 4 artikel.

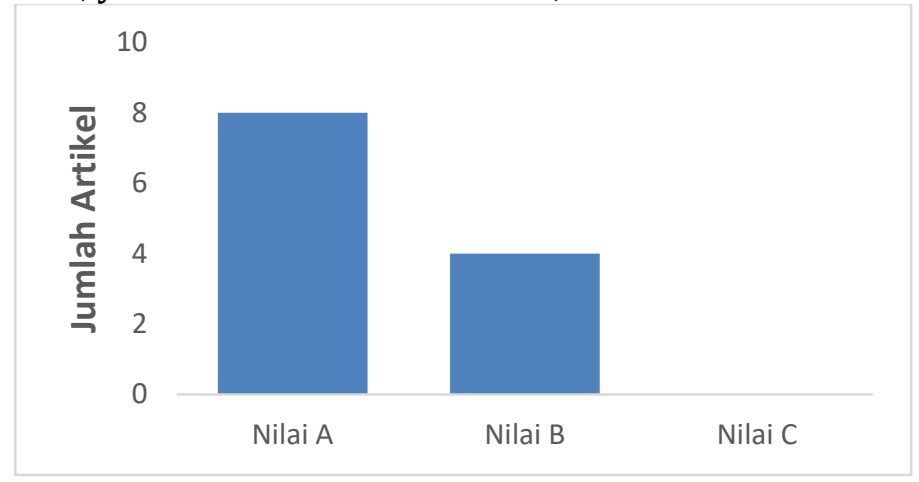

Gambar 3.3. Analisis Berdasarkan Kualitas/ Nilai Artikel

Tahapan selanjutnya yakni memetakan tema berdasarkan artikel yang dipilih, dengan ditemukan sebanyak 2 tema yaitu berdasarkan: faktor internal: dukungan dan pengetahuan , faktor ekternal: lingkungan kerja, pengalaman.

Tabel 3.4. Mapping tema Pengalaman Praktik Pemberian ASI Eksklusif Pada Ibu Bekerja

\begin{tabular}{|l|l|}
\hline \multicolumn{1}{|c|}{ Tema } & \multicolumn{1}{c|}{ Artikel } \\
\hline $\begin{array}{l}\text { a. Faktor internal : dukungan } \\
\text { dan pengetahuan }\end{array}$ & $\begin{array}{l}\text { Riaz \& Condon (2019), Nkrumah (2017, Mabaso } \\
\text { et al.(2020), Cervera-Gasch et al (2020), Chen et } \\
\text { al (2019), Sari et al. (2015) }\end{array}$ \\
\hline $\begin{array}{l}\text { b. Faktor eksternal : } \\
\text { lingkungan kerja, } \\
\text { pengalaman }\end{array}$ & $\begin{array}{l}\text { Valizadeh et al. (2017), Hasan et al. (2020), Dun- } \\
\text { Dery \& Laar (2016), Abekah-Nkrumah et al. } \\
(2020)\end{array}$ \\
\hline
\end{tabular}

Review ini untuk mengeksplorasi pengalaman praktik pemberian ASI eksklusif pada ibu bekerja dan mengumpulkan data tentang pengalaman praktik ASI eksklusif di tempat kerja. Hasil temuan secara sistematis didapatkan dari data yang diekstraksi dari artikel scoping review ini 
disusun dalam beberapa tema yaitu: faktor internal: (dukungan keluarga, pengetahuan) dan faktor eksternal: (lingkungan kerja, pengalaman).

\section{Internal}

1. Dukungan keluarga

Berdasarkan penelitian Truong Xuan NT \& Nguyen NT (2018) (20) semua ibu yang bekerja mengaku mendapat dukungan yang besar dari anggota keluarga. Para ibu tidak melakukan apaapa ketika kembali kerumah, melainkan menghabiskan banyak waktu untuk bayi saat dirumah hal itu membuat ibu merasa bahagia dan perasaan itu sangat baik untuk ibu. Namun berbeda dengan pendapat Abekah-Nkrumah et al. (2020) (14) beberapa ibu menyebutkan masalah ketidakseimbangan pekerjaan dengan dukungan keluarga sebagai faktor yang menghambat kemampuan ibu bekerja untuk memberikan bayinya ASI secara eksklusif. Suaminya juga memperebutkan bayinya agar mendapatkan ASI dan hal ini ternyata berdampak antara pekerjaan dan kehidupan keluarganya serta buruk pada kesehatan fisik ibu menyusui tersebut.

\section{Pengetahuan}

Berdasarkan penelitian (Cascone et al., 2019) (23) meskipun kesadaran tentang ASI eksklusif diantara ibu yang bekerja professional hampir universal (99\%), tetapi praktik ASI eksklusif masih rendah. Ibu yang memiliki pengetahuan tentang pemberian ASI eksklusif hanya sebagian kecil yang melakukan praktek pemberian ASI eksklusif. Adanya pemahaman yang berbeda tentang ASI eksklusif ini0menimbulkan tidak yakin pada diri ibu bekerja untuk memberikan ASI eksklusif. Berbeda dengan penelitian Hasan et al. (2020) (19) persepsi dan keyakinan ibu bekerja tentang ASI eksklusif ini sangat mempengaruhi keberhasilan praktik menyusui dan pendidikan tentang menyusui harus dilakukan secara berkelanjutan agar ibu bekerja memberikan ASI eksklusif hingga berusia 6 bulan.

\section{Eksternal}

\section{Lingkungan kerja}

Valizadeh et al. (2017) (17) mengemukakan beban kerja yang terlalu banyak dapat membawa tekanan pada ibu sehingga mempengaruhi pemberian ASI, ibu dapat mengatasi beban kerja tersebut. Dengan membantu menyelesaikan tugas pekerjaan, bahkan mengizinkan calon ibu untuk memompa ASI agar berhasil mendapatkan ASI eksklusif, mereka mendapatkan dukungan aktif dari rekan kerja. Menurut Mabaso et al.(2020) (16) menyatakan salah satu penghambat menyusui setelah kembali bekerja yaitu kebijakan cuti yang tidak mendukung proses pemberian ASI. Beberapa ibu memilih untuk tidak mengajukan perpanjangan cuti melahirkan karena tidak dibayar dan ada kebutuhan finansial untuk kembali bekerja, sebagian besar ibu menceritakan bahwa selama cuti melahirkan mereka mulai cemas memikirkan bagaimana memberikan nutrisi yang optimal untuk bayinya setelah kembali bekerja.

\section{Pengalaman}

Para ibu yang bekerja menyuarakan pengalaman negative mereka dengan pemberi kerja dan rekan kerja yang tidak mendukung dengan menyusui dan kebutuhan mereka untuk memeras ASI (13) tetapi ada pengalaman berbeda, para ibu belajar dari pengalaman para ibu senior yang sudah lama bekerja dan tetap memberikan ASI eksklusif (18). Para ibu merancang tempat kerja mereka agar memastikan bahwa aktivitas menyusui mereka tetap berjalan tidak mengganggu perasaan 
rekan kerja mereka yaitu dengan cara memerah ASI mereka baik secara manual atau dengan pompa ASI. Oleh karena itu pengalaman mereka dan strategi yang mereka adopsi mungkin tidak berlaku untuk perempuan yang bekerja atau tempat kerja yang berbeda.

\section{Kesimpulan}

Praktik pemberian ASI eksklusif pada ibu bekerja masih rendah. Beberapa faktor disebabkan menjadi penghambat dalam keberlangsungan proses pemberian ASI eksklusif, diantaranya dukungan keluarga, suami, rekan kerja, lingkungan kerja, fasilitas di tempat kerja (cuti melahirkan, memfasilitasi daycare, ruang laktasi atau pojok ASI, alat pompa ASI), pengalaman menyusui, dan pengetahuan. Harapan ibu bekerja yaitu membutuhkan dukungan tertentu seperti istirahat untuk memerah ASI, ruangan khusus untuk memerah ASI, dan setiap tempat kerja memfasilitasi penyimpanan ASI.

\section{Ucapan Terimakasih}

Penulis mengucapkan terima kasih kepada program Magister Kebidanan, Fakultas Ilmu Kesehatan, Universitas 'Aisyiyah Yogyakarta yang telah memfasilitasi studi ini.

\section{Konflik Kepentingan}

Penulis menyatakan bahwa artikel ini tidak ada konflik kepentingan.

\section{Referensi}

1. WHO. Exclusive breastfeeding for optimal growth, development and health of infants. eLibrary of Evidence for Nutrition Actions (eLENA). 2019.

2. Kemenkes RI. Profil Kesehatan Indonesia Tahun 2019. Kementrian Kesehatan Repoblik Indonesia. 2019.

3. Siregar MA. Pemberian ASI Eksklusif dan Faktor-faktor yang Mempengaruhi. Gizi. 2014;

4. Anggraeni IA, Nurdiati DS, Padmawati RS. Keberhasilan ibu bekerja memberikan ASI eksklusif. J Gizi dan Diet Indones (Indonesian J Nutr Diet. 2016;

5. Novayelinda R. Telaah literatur : Pemberian ASI dan Ibu Bekerja. J Ners Indones. 2012;2(2):177-84.

6. Astuti AW, Morgan R. Interventions analysis of addressing exclusive breastfeeding (EBF) barriers to improve EBF coverage among industrial women employees in indonesia. J Heal Technol Assess Midwifery. 2018;1(1):1-16.

7. Agustia N, Machmud R, Usman E. Faktor yang Berhubungan dengan Pemberian ASI Eksklusif pada Ibu Bekerja di Kabupaten Ogan Komering Ulu. J Kesehat Andalas. 2019;

8. Charlick SJ, McKellar L, Gordon AL, Pincombe J. The private journey: An interpretative phenomenological analysis of exclusive breastfeeding. Women and Birth. 2019;

9. Askey, H. O'Malley L. Scoping studies: towards a methodological framework. Int J Soc Res Methodol. 2009;

10. Hong Q, Pluye P, Fàbregues S, Bartlett G, Boardman F, Cargo M, et al. Mixed Methods Appraisal Tool (MMAT), Version 2018. User guide. McGill. 2018;1-11.

11. Nkrumah J. Maternal work and exclusive breastfeeding practice: A community based cross-sectional study in Efutu Municipal, Ghana. Int Breastfeed J. 2017;

12. Cervera-Gasch Á, Mena-Tudela D, Leon-Larios F, Felip-Galvan N, Rochdi-Lahniche S, Andreu-Pejó L, et al. Female employees' perception of breastfeeding support in the workplace, public universities in Spain: A multicentric comparative study. Int J Environ Res Public Health. 2020;

13. Dun-Dery EJ, Laar AK. Exclusive breastfeeding among city-dwelling professional working 
mothers in Ghana. Int Breastfeed J. 2016;

14. Abekah-Nkrumah G, Antwi MY, Nkrumah J, Gbagbo FY. Examining working mothers' experience of exclusive breastfeeding in Ghana. Int Breastfeed J. 2020;

15. Riaz S, Condon L. The experiences of breastfeeding mothers returning to work as hospital nurses in Pakistan: A qualitative study. Women and Birth. 2019;

16. Mabaso BP, Jaga A, Doherty T. Experiences of workplace breastfeeding in a provincial government setting: a qualitative exploratory study among managers and mothers in South Africa. Int Breastfeed J. 2020;

17. Valizadeh S, Hosseinzadeh M, Mohammadi E, Hassankhani H, M. Fooladi M, Schmied V. Addressing barriers to health: Experiences of breastfeeding mothers after returning to work. Nurs Heal Sci. 2017;

18. Payne D, Nicholls DA. Managing breastfeeding and work: A Foucauldian secondary analysis. J Adv Nurs. 2010;

19. Hasan AMR, Smith G, Selim MA, Akter S, Khan NUZ, Sharmin T, et al. Work and breast milk feeding: a qualitative exploration of the experience of lactating mothers working in ready made garments factories in urban Bangladesh. Int Breastfeed J. 2020;

20. Truong Xuan NT, Nguyen NT. BREASTFEEDING EXPERIENCES OF WORKING MOTHERS IN VIETNAM. Belitung Nurs J. 2018;

21. Sari Y, S. Y, V. N. The exclusive breastfeeding experiences of working mothers in West Sumatera (Sumbar) Peduli ASI community. Int J Res Med Sci. 2015;

22. Chen J, Xin T, Gaoshan J, Li Q, Zou K, Tan S, et al. The association between work related factors and breastfeeding practices among Chinese working mothers: A mixed-method approach. Int Breastfeed J. 2019;

23. Cascone D, Tomassoni D, Napolitano F, Di Giuseppe G. Evaluation of knowledge, attitudes, and practices about exclusive breastfeeding among women in Italy. Int J Environ Res Public Health. 2019; 